\title{
10 Care, Generations and Reciprocity in Children's Picturebooks in Japan
}

\author{
Katsura Sako and Sarab Falcus
}

\section{Introduction}

The COVID-19 pandemic brought into sharp focus questions about care, dependence and relationality. It highlighted, in particular, the generational relationship as something that is critical to the care and health of populations. As age was identified as a marker for vulnerability to the virus, yet resources for care were often severely limited, the question of which generations to protect and care for had ethical, political and social implications. Generational connection, however, has long been a critical issue in debates about care in Japan. Anxieties about care in the country connect the oldest and the youngest in the population through the twin drivers of demographic change: increased longevity and low fertility rates. Long life expectancy and the low birth rate combine to create a "super-aged population" (Kavedžija 215), pushing up the country's oldage dependency ratio and the demand for health and social care. ${ }^{1}$ More broadly, generational connection is a grave concern, because the country has long relied on families in the provision of care for older generations, and yet demographic, cultural and social changes have made such family-based care increasingly unsustainable. While social and publicly provided care remains inadequate, there is also a growing concern about the neoliberal individualisation of care responsibility. Chizuko Ueno, one of the leading feminist scholars on the family and care in Japan, therefore argues that "the myth of 'familial care' must be deconstructed" to realise a social security system that better responds to the varied circumstances and care needs of older people (Kea 104; translation by Sako).

To explore the cultural discourse of ageing, illness and care through the lens of generations, in this chapter we analyse post-1980 Japanese picturebooks that depict generational relations and care in a familial context. Children's literature is a genre in which the adult-child relationship is ingrained. Children's texts are produced largely by adults; are then often bought by adults; and even, in the case of books for the youngest, read by adults to children. Though there is a small but growing body of scholarly work on children's literature and ageing (see for example 


\section{Katsura Sako and Sarah Falcus}

Henneberg; Joosen, Connecting Childhood and "Second Childhoods"), studies that explore ageing, old age and intergenerational relationships in Japanese children's literature are very limited (Aoyama; Oomachi). The present study rectifies this by examining the relationship between the child and the older adult (usually a grandparent) in contemporary Japanese picturebooks. Our analysis is informed by Japanese, AngloAmerican and European scholarship. We heed the warning that Western perspectives are "often uncritically presumed to be culture-free and universally valid" (Lamb 37). We hope, however, that our eclectic intellectual basis enables a contextually informed reading that may also have relevance for similarly neoliberal, capitalist societies with ageing populations and increased demands for care.

There are debates and concerns among scholars over the power imbalance inherent in a literature (largely) written by adults for children (Nikolajeva; Nodelman) and the disempowerment of the child in many approaches to that literature (Gubar; Rudd). Nonetheless, in this chapter, we deliberately approach these books from the perspective of the adult. This approach recognises the significant role that picturebooks, or more generally children's literature, have played as an educational tool for children in Japan, a role that may extend to shaping the cultural discourse of family care. From the late nineteenth century through to the end of the Second World War, Japanese children's literature in its modern forms developed in close relation to the state's official policies and efforts to bring about modernisation and development, meaning that the books still often carry a strong instructive force (see for example Karatani Ch. 5; Torigoe, "Sengo"). Didacticism has characterised many picturebooks, too, since their modern forms began to be published in the early twentieth century (see for example Honda, "Ehon" 124-27 and Kodomo 201-08). This tendency continued even as picturebooks moved away from the militarism of the previous decades, and throughout the "golden age" of the genre (the 1960s through to the 1990s), which witnessed its expansion and diversification (Torigoe, Hajimete 146). The Ministry of Education, Culture, Sports, Science and Technology's 1956 guideline recommended the use of picturebooks for education at kindergarten; picturebooks were widely circulated through school and community libraries (Takahashi 147-51); the School Library Association (SLA) and other educational bodies began - and continue - to issue lists of recommended picturebooks; tied to these lists, various reflective writing competitions for children have been held locally and nationally (Miura 188-9; Torigoe, "Sengo" 14). ${ }^{2}$ This instructive impulse is reinforced by the way in which the adult's voice is felt in the books, because the act of address as well as the age and the gender of the addressee and the addressed are often clearly indicated in the modern Japanese language (Karatani Ch. 2). Therefore, there may be more 
explicit didacticism in Japanese picturebooks than in those produced in other cultures.

We present in this chapter our findings from a survey of 46 Japanese picturebooks, chosen from a larger corpus of 75 picturebooks about intergenerational, primarily (great) grandparent-grandchild, relationships. ${ }^{3}$ We explore the various ways in which these books promote the traditional - generational and gendered - form of familial care. These books depict two types of care: one is emotional, practical and affective care, and the other is what Eva Feder Kittay, Bruce Jennings and Angela A. Wasunna call "dependency care," in which a person (young or old) needs support in the daily activities of self-maintenance (443-4), a type of care that is central to policies and debates about care in Japan. But we are less concerned with exploring different types of care in the books than with the way that care is both realised and anticipated, underpinned by notions of duty, responsibility and reciprocity. As our analysis demonstrates, these notions are often expressed through narratives of generational succession that link care to intergenerational reciprocity, something that may reflect the adult's desire to secure care in the future. Akiko Hashimoto describes this generational exchange of care in Japan in her 1996 study: "The expectation that succeeding generations face the same predicaments creates the basis for reciprocal helping arrangements that extend over generations: The young person is more likely to pay the price of old age willingly at an early age, if he or she also expects need is inevitable and wants to guarantee his or her future support" (150). These books are then a medium that perpetuates rather than deconstructs what Ueno calls "the myth of 'familial care"" (Kea 104).

The family care depicted in these picturebooks can be read in the light of the ideas of relational care and self associated with feminist ethics of care (Gilligan; Kittay; Noddings). The focus on relationality in this scholarship derives from a feminist rethinking of the conception of the human subject as an autonomous self in the Western liberal tradition, a conception that does not accommodate conditions such as vulnerability, disability and resultant dependency. Scholars such as Kittay have argued that dependency must be considered as an inevitable and shared condition of human subjects. This approach resonates with age studies critics who question discourses of successful ageing that are founded upon ideals of "individual choice, agency, and lifestyle" (Katz and Calasanti 28). On one level, these picturebooks suggest a relational model of care, one that accommodates rather than stigmatises dependency and an embodied, potentially vulnerable self. The integration of care responsibility into the family as a self-sufficient unit means that the books tend not to stigmatise the receipt of care. At the same time, however, the books contribute to a social imaginary that idealises gendered care. As feminist care ethics scholars have noted, social structures can create and amplify the vulnerability of certain people, including carers, most of whom are women 
(Kittay et al. 462). Furthermore, some books also suggest a paradox at the heart of familial relationality: that it can lead to anxieties around dependency on others and can restrict the ways in which autonomy is exercised.

The relationality of care and self that we find in these books in many ways echoes existing scholarship on subjectivity and autonomy in Japanese culture. ${ }^{4}$ For instance, John Traphagan explains: "in many respects it makes more sense to talk about family autonomy than individual autonomy in Japan" (Rethinking 77). There are also suggestions that a specific form of individualism underlies the collectivist fabric of Japanese society. ${ }^{5}$ These suggestions indicate the complex positionality of self in relation to others and groups in Japan, and we certainly do not deny the similarities between this scholarship and some of our conclusions about the books we examine. Indeed, the specific ways in which autonomy and reciprocity are exercised in these books do suggest that the impact of local culture cannot be ignored when we think, read and write about care, reminding us of Lamb's caution about the non-universality of Western theorisations. Nonetheless, it is not our aim in this chapter to participate in the debates about contemporary Japanese selfhood. Our primary concern is to explore the role of children's picturebooks in the discourse of care in Japan and how they depict the familial relationality that sustains reciprocal care.

\section{Familial Care in Japan}

Ueno defines family care as that in which the primary carer is kin to the cared-for, which is unpaid and which takes place in the residence of the cared for ("Family Strategy" 31). There is the popular belief in and outside of Japan that family care - especially that based in a multigenerational household - is part of Japan's cultural tradition. Scholars have shown, however, that this belief is a product of official policies and political discourses. Merry White explains that "the family" is a state construct invented by the Meiji government (1868-1912) to achieve rapid industrialisation through the gendered division of labour ("Introduction"). In this system, care responsibility was located in each family and fell to female members, especially daughters-in-law, in cases of elder care. Studies have also identified the "contractual quality" (Coulmas 64) of family care that undermines the view that it is sustained solely by filial piety. Misa Izuhara notes, for instance, that inheritance practices in Japan, although changing, have traditionally been linked closely to the care that the child has provided for the parent. Looking at care relationships in both Japan and America, Hashimoto also describes the "social contract" that underpins care relationships as "a reciprocal arrangement to give and receive gifts in turn, based on a tacit standard of evaluation that defines their symbolic equivalence" (17). She argues that in Japan 
there is greater expectation of the need for care, and this leads to the involvement of the family in planning for future care needs. This expectation of the need for care also shapes relationships among generations as "intergenerational equity means taking turns in giving and receiving support according to differential abilities in different life stages" (Hashimoto 154).

Despite the continued emphasis upon familial and intergenerational responsibility in cultural discourses and in practices of care, the reliance on gendered and generational care has come under increasing pressure in the decades since the end of the Second World War. This is due to various factors: growing female participation in higher education and the labour market; the reduction of multi-generational households and an increase in nuclear households as a result of ongoing rural to urban migration; ${ }^{6}$ and the decline of secure and stable employment in post-recessionary Japan (Aoyama et al. 1-2; Sasaki), contributing to the increase in single-person households and late marriage; and a growing segment of the population who never marry. Alongside these changes, there have been debates over and reform to the social security and welfare and healthcare systems for older people since the achievement of basic universal healthcare coverage in the 1960s (Nakagawa and Gondo). The Act on Social Welfare for the Elderly in 1963 was a response to the ageing population and the associated idea of care as a "social problem." Public care provision, however, was limited and only available to those for whom familial care was not available. There were further reforms to welfare, healthcare and the pension system throughout the seventies, eighties and nineties, as demographic change continued. The Long-Term Care Insurance (LTCI) system, introduced in 2000, marked a significant milestone, combining social insurance and tax to provide more public care (Nakagawa and Gondo 57). LTCI has, however, contributed to the rapid marketisation of care and the individualisation of care responsibility, leaving many older people unable to afford the care they need (Nakagawa and Gondo; Thang). ${ }^{7}$ More significantly, the system has been criticised for assuming family involvement in care, making it "a useful tool to keep the family involved in the care of older people" (Tokoro 68).

Despite expanding social and private care, therefore, many families continue to cope with care responsibilities. Yet, signs of the limits of familial care indeed abound: a rising poverty rate among older populations; the rising number of older people who live and die alone in their homes; ${ }^{8}$ continuing incidents of abuse and violence against older people by family carers, despite the 2006 Law for the Prevention of Elderly Abuse and Support for Caregivers; and cases of "old-old care" (ro ro kaigo), where carers themselves are old and are often caring with severely limited resources (see Kasuga). Care also remains a gendered issue. Although forms of family care have diversified, with more men caring for spouses and parents, care is still predominantly undertaken by women, as wives, 


\section{Katsura Sako and Sarah Falcus}

daughters and daughters-in-law, ${ }^{9}$ in many cases making them financially and emotionally vulnerable (Ueno, Kea 112-15).

These recent changes have unsettled the generational exchange of care, confirming Hashimoto's claim that "intergenerational equity is not set in stone" (155). Furthermore, to suppress care costs, governmental discourses and initiatives place increased emphasis on the prevention of care needs and support for independence (Arichika et al.). Ethnographical works confirm the impact of these changes in the lives of older people. For instance, Jason Danely emphasises how some older people now live with the fear of falling out of the circles of care within families and communities and being abandoned (Ch. 6); "If Japan was never a genuine geriatric utopia," he states, "then it is not currently a paradise lost" (17). The generational care in the picturebooks we examine, however, remains largely anachronistic and nostalgic, suggesting a desire to sustain a discourse of familial care, even in the face of social change.

\section{The Picturebooks: An Overview}

Our corpus contains 46 books published between 1982 and 2015. Many are published by well-known or established publishing houses specialising in children's literature, and some are widely circulated. ${ }^{10}$ The readership age groups for these books are judged to be up to around eight years old. ${ }^{11}$ The narratives in the corpus are predominantly realist, although there are exceptions, such as the fantastic elements in Obachan to warabeuta [Grandma and Nursery Songs] (Nakajima, Takagi and Ikeda, 1997) and Maho ha naishode kakeyone [Let's Secretly Cast a Spell] (Sueyoshi and Makino, 1984). ${ }^{12}$ The illustrations in the books are similarly realist, but they do include symbolic and carnivalesque elements, for example, in Bachan no onaka [Grandma's Tummy] (Kasai and Yoshinaga, 2010).

One-third of the books in the corpus are clearly set in multi-generational households, and this proportion does not change significantly in the books from the twenty-first century, despite the rise in nuclear families and single-person households in Japan. Grandparents are most often widowed and are rarely seen in couples, a feature that may be a reflection of Japanese households as well as a conceit to allow for an intimate child-grandparent relationship. Some narratives employ what Vanessa Joosen (Connecting 17) calls the "seesaw effect," omitting the middle generation (the child's parents) in order to exploit the child-older person bond for narrative effect. In 14 books, grandparents are seen at home in need of care because of injury, impairment or illness; in 4 books, grandparents receive medical care at hospital. Significantly, the middle generation is typically present in the narratives in which dependency care for grandparents is required and the child's parents (predominantly mothers) are seen to have a caring role within the family. Only two of the books contain representations of day-to-day professional, non-medical care at 
and outside of the home. ${ }^{13}$ This means that these books largely ignore the recent increase in professional care and diversifying forms of familial care in Japan mentioned earlier.

Grandparents are not always care recipients, and both grandfathers and grandmothers provide care for children in these books. Nonetheless, representations of older people are strongly heteronormative and gendered, despite the diversification of gender representations in Japanese picturebooks in recent decades noted by scholars such as Kyoko Takeda ("Gender"). Most books are centred on (great) grandparent and grandchild relationships, with same-sex pairings the most common: 17 books feature (great) grandfather/grandson relationships and ten books feature (great) grandmother/granddaughter pairings. Where the relationship is of mixed sexes, grandmother/grandson pairings appear most frequently (ten books), with only one book featuring a relationship between a granddaughter and grandfather. Although the gender balance of grandparents is almost equal, in our sample, grandfathers are very rarely seen with and caring for female children. Grandmothers are depicted with white hair, wrinkles and round bodies; they are tied to domestic environments and undertake tasks such as cooking and childcare. In earlier books, they are often depicted as physically frail (Yukkurayukkura yotayota [Slowly, Slowly, Titter, Tatter] (Watanabe and Kajiyama, 1982); Obachan no engawa [Grandma's Deck] (Nomura, 1983)). Later books offer stronger grandmotherly figures - even to a baseball-playing grandmother in Obachan ga obachan ni nattahi [The Day Grandma Became Grandma] (Nagano, 2015) - but this strength is exerted within the parameters of the maternal and domestic role. Grandfathers, on the other hand, are more varied. They range from stern, blue-collar figures (Jishinkaminarikaji jichan [Earthquake, Lightning, Fire, Grandpa] (Okada and Shinohara, 1987); Jichan to naishonaisho no yamanobori [A Secret Secret Mountaineering with Grandpa] (Watanabe 2007)) who speak in a rough, masculine language and rarely smile, to more caring (It's Okay, It's Okay) and imaginative figures (Let's Secretly Cast a Spell; Futari ha dadakko [Two Spoiled Children] (Imamura and Furiya, 1995)). The trend overall is, nevertheless, to stress the masculine role and to locate grandfathers outside the home, very often connected to rural and even wild places. These findings may not be statistically significant because of the small size of our sample, yet they are suggestive of the persistence of the link between gender and familial care.

\section{Care, Duty and Intergenerational Reciprocity}

Care in these books is embedded within gendered generational structures and is presented as a duty that is tied to one's position in the family. Many of the books offer a clear moral lesson about a child's responsibility to care and depict the obliging child who matures through care. This 


\section{Katsura Sako and Sarah Falcus}

is facilitated by presenting care as a challenge to the child but also as an opportunity for their growth. Most of the books that depict the illness of a grandparent present this as an acute or temporary rather than chronic condition, which ends with the grandparent's recovery or death. A grandparent's illness is therefore an event that clearly marks the exchange of caring roles between the generations, emphasising the development of the child. The narrative of reciprocal generational care in these books therefore aligns with Miyuki Hisaoka's observation in a comparative study of Japanese and Australian picturebooks that Japanese texts envisage subjectivity based on "identity-with" rather than "different-from" as their Australian counterparts do (71). This distinction may be cultural, as Hisoaka suggests, and rest on the idea that Japanese subjectivity "tends to be formed in wider society through the child's early joining into social practices," practices that encourage their "assimilation ... into society" (76). The books we examine certainly support a vision of personhood and child development that is based upon relationality and obligation. What is important for our discussion, however, is that this relational model of subjectivity is embedded within a narrative of development that teaches the child about the duty to care.

In Yuko to Fumi bachan [Yuko and Grandma Fumi] (Miyakawa and Ishikura, 1983), the acceptance of a generationally defined role and gendered care responsibility is powerfully depicted through mirrored generations. Grandma Fumi relates to her grandchild, Yuko, a story about caring for her own mother, Yuko's great-grandmother, when she was ill. Grandma Fumi goes to great lengths to find snow on the mountain and brings it to cool her mother's fever. Grandma then falls ill, and Yuko undertakes the same task, travelling far into the mountains to find snow. The repetition of this story is reinforced by the mirroring of images within the text. In a double spread, a red-clothed, young Grandma Fumi kneels beside her mother's futon (see Figure 10.1) and, in a later image, walks in the mountains, small against the landscape. Similarly, Yuko is seen as a figure in a red skirt kneeling next to her grandmother's futon (see Figure 10.2) and then as a small figure against a mountainous background. Grandma recovers, just as her own mother did, as a result of the care of the child. Grandma, like her mother before her, praises this care when in the company of other members of the community, making clear the social value of familial care and responsibility.

Children travelling to and visiting older relatives alone is a repeated trope in the books that reinforces the moral education of the child through the fulfilment of a caring role (Grandma's Tummy; It's Okay, It's Okay; Obachan no shima de [On Grandma's Island] (Furiya, 1995); Hitoride omimai [A Visit Alone] (Kimura and Kimura, 1991); Sayonara, obachan [Goodbye, Grandma] (Nishimoto and Karino, 2010)). In her study of the long-running series of stand-alone picturebooks, Kodomonotomo, Takeda argues that nuclearisation of families "ha[s] detached the presence 

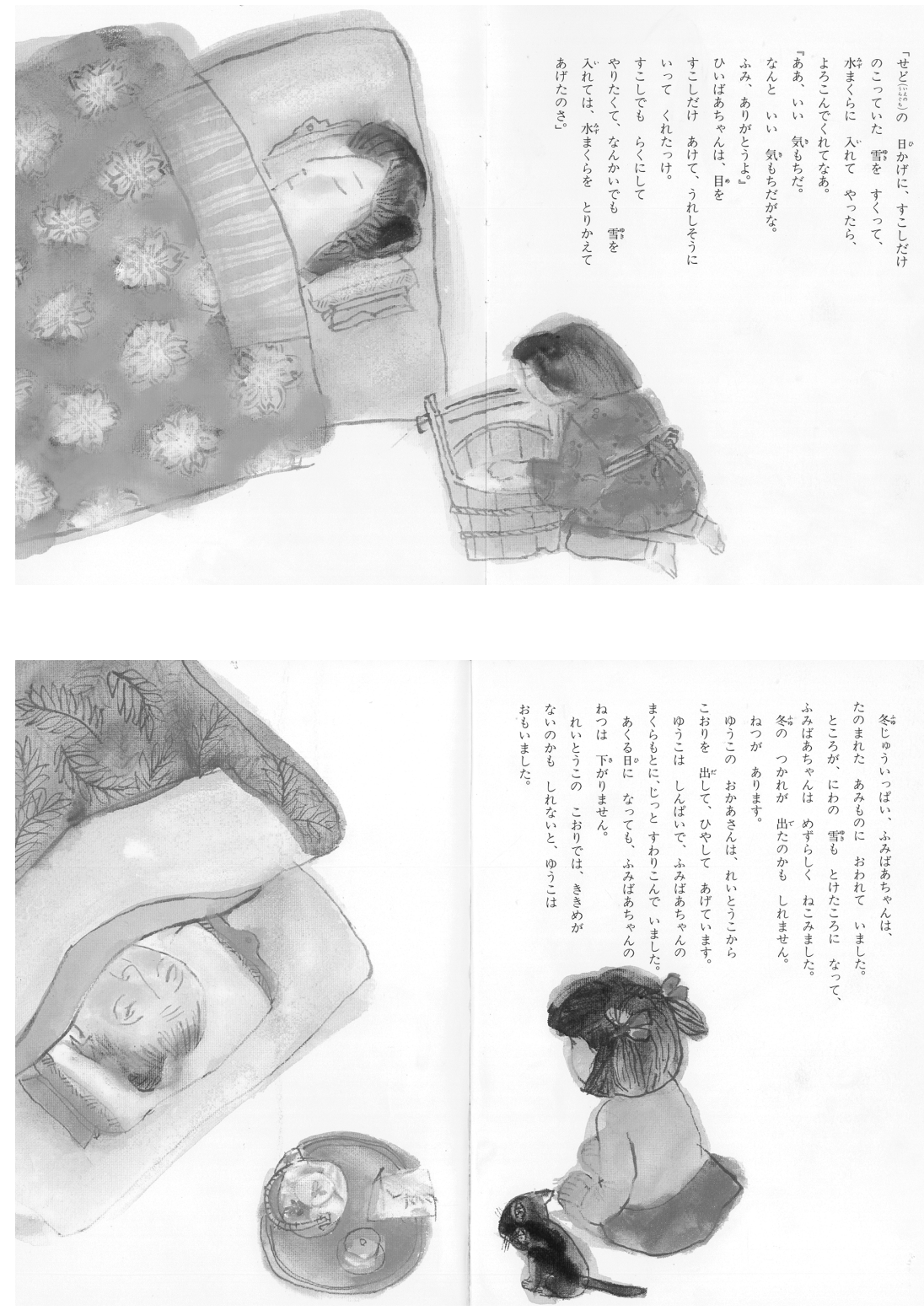

Figures 10.1 and 10. 2 Yuko and Grandma Fumi [Yuko to Fumi bachan], reproduced with permission of Akane Shobo.

Source: ( Hiro Miyakawa and Kinji Ishikura. 
of grandparents from children's daily life" ("Ehon" 526), noting a growing number of books where grandparents live alone, or where a child visits a grandparent during long school holidays (ibid. 527). The journey narrative may reflect changing household structures in Japan, which means generations are geographically separated, with grandparents living in rural or remote areas in some cases. Nonetheless, as a device, this trope effectively represents a journey to maturity and emphasises the child's responsibility for care within a generational structure.

In the more recent picturebook Obachan ha kaguyahime [Grandma is Kaguyahime] (Matsuda and Karino, 2013), Saki-chan visits her father's childhood home to stay with her bamboo-farming grandparents alone for the first time. This indicator of child development is tied closely to generational responsibility, as Saki-chan's father tells her that "Grandpa and Grandma are both old now. It's crucial that you dig up bamboos every day" (3). He worries that the child will not "be enough help" (ibid. 3.). The bamboo functions as a symbol on a number of levels: it ties the grandparents to a traditional occupation, it represents their livelihood and independence, and its encroachment is a danger associated with lack of care. This is made clear in the example of a neighbour's house where the bamboo growing out of the floor is explicitly connected by Grandpa to the lack of family and, implicitly, to the lack of care and support. As Grandpa says, "Apparently there's bamboo growing out of the floor at Ueda-san's house. They don't have any kids and they can't take care of the house nor the mountain, only bamboo's growing” (20). The book uses temporary illness as a plot device in order to enable the child's development through responsibility and duty. The care that the grandparents are seen giving to Saki-chan is reciprocated when her grandmother injures her foot and Saki-chan is seen in the image bending down to her seated grandmother, trying to help. A later image depicts Saki-chan stooping to touch her grandmother's injured foot. These images of care are supplemented by a narrative that describes Saki-chan helping her grandfather to dig bamboo shoots in order to make her grandmother happy. As in many other books, illness necessitates the reversal of the caring role, tying the development of the child to their place in a generationally defined structure of care and responsibility.

Significantly, this generational responsibility is gendered in distinctive ways. One example is the way that Grandma is Kaguyahime alludes to the traditional literary tale of Kaguya-hime [Princess Kaguya], a story about a girl who is found in a bamboo stalk, raised by an old couple, and grows into a beautiful woman. Grandpa tells Saki-chan that Grandma was known as Kaguya-hime as a young girl, and that Saki-chan is their Kaguya-hime. The allusion to Kaguya-hime connects Grandma (as child) and Saki-chan through their appearance (emphasised in Grandpa's words and in the large image of Kaguya-hime centred on the page), their affinity with bamboo, and their status as a source of happiness for older adults. 
This connection is embedded within the familial unit when Saki-chan's parents return and her father joins Grandpa in cutting bamboo. The double spread presents the active masculinity of the grandfather and the father as they climb the mountain carrying tools, in opposition to the stasis of the three women. In the image, the mother supports a slightly stooping Grandma as Saki-chan raises her hands towards the men above her. The sense of generational succession that is evoked by the Kaguya-hime tale is reinforced by the narrative of generational responsibility and emphasised by images that depict gendered, generational structures of care.

The moral lesson is particularly strong in books that depict a child's resistance to care and to their familial obligations. In a number of books, the child protagonist is seen to struggle with the role expected of them in relation to an older relative (for example, Grandma and Nursery Songs). In Chiko-chan no akai chokki [Chiko-Chan's Red Vest] (Furiya, 1987), a grandmother's illness marks the shift of her role from the provider to the recipient of care, and granddaughter Chiko-chan initially struggles with the repercussions of this. Chiko-chan's relationship with her grandmother is established in an image of them planting bulbs together, both active and smiling. The garden and the cycle of the seasons then provide the temporal framework and symbolism for the narrative of their changed relationship. The outdoor space proves to be a space of risk for the grandmother: her two falls - one in the garden and the other through the bedroom window - cause her confinement to her futon. The indoor space then becomes one of illness and, therefore, of care. After her collapse, the grandmother is primarily depicted indoors, and Chiko-chan, coming back from school, sees her bedroom window curtained. The grandmother is then seen in bed or looking out from her bedroom window, symbolically representing her changed relationship with the world around her, including both the garden and her granddaughter.

Care is heavily gendered in Chiko-chan's Red Vest. Published in 1987, just two years after the passing of the Equal Employment Opportunity Law in 1985, the book contains a rare representation of a working mother. Nonetheless, though both parents discuss the burden of care, it is the mother in this multi-generational household who leaves her job to provide care for her ill mother-in-law. Many images show her smiling whilst providing practical support with feeding and other daily activities (see Figure 10.3).

Yet Chiko-chan is also still in need of the mother's care, as suggested by an image of her trailing after her mother, holding onto her apron. Chiko-chan is depicted as an observer in the images of her mother caring for her grandmother, looking askance and at times shocked by her grandmother's changed behaviour and inability to care for herself. In one image, Chiko-chan is seen holding her nose and the text describes her complaining about the smell of the room. However, as a narrative of growth and development, the picturebook sees Chiko-chan learn to relate 


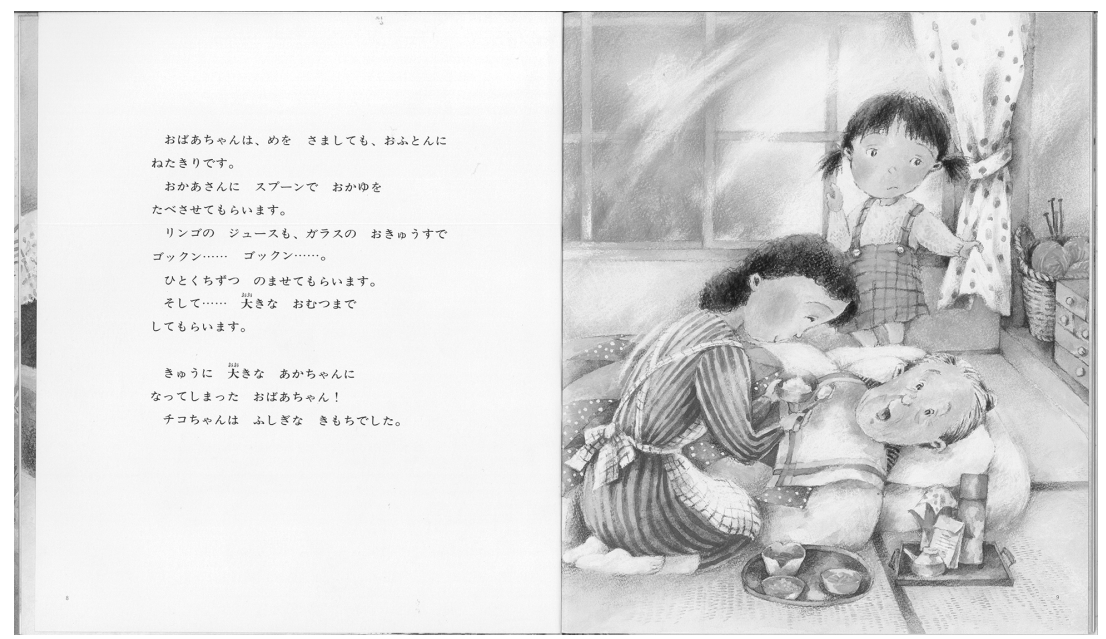

Figure 10.3 Chiko-chan's Red Vest [Chiko-chan no akai chokki], reproduced with permission of Kayoko Furiya.

Source: (c) Kayoko Furiya.

to and care for her grandmother. This is symbolised by the first image of the grandmother outdoors after her collapse: she is seen sitting making flower crowns and necklaces with her willing granddaughter. Spring has arrived, and in the following double spread the hyacinths planted by the pair have bloomed, linking generational succession (and the human life course) to the cycle of the seasons. The child reader is encouraged to empathise with and relate to Chiko-chan's initial struggles and her final, and inevitable, acceptance of her gendered caring role. The gendered nature of this role is emphasised in an image in which a male doctor and Chiko-chan's father are depicted sitting next to the dying grandmother, with the mother and Chiko-chan sitting behind them. The book's narrative of generational succession is then reiterated after the grandmother's death when the mother completes a red vest that the grandmother had been making for Chiko-chan, symbolically taking on the grandmother's role and linking the three generations of women through a domestic skill. Chiko-chan is currently the recipient of her mother's care, but the text implies that she will, in her turn, become the provider of care to both her elders and to the next generation.

In contrast to grandmother-granddaughter relationships, relationships between grandfathers and grandsons are often marked by active, commonly outdoor pursuits that enable the succession of traditionally masculine skills and knowledge through generations. Care, in this trope, 
is not practical support for daily life, but embodied in the assumption of intimately shared masculine knowledge and skills as familial assets. Furthermore, what is notable about these books is that the vision of masculinity being passed on to the child is one under threat, but this threat is contained through the male lineage. The sense of anxiety that emerges in some of these texts intimates that changes in Japan are unsettling the vision of familial care promoted by the books. In Earthquake, Lightning, Fire, Grandpa, for example, a grandfather teaches his grandson the traditional family trade, bamboo weaving, and this functions as a compensation for the loss of the family bamboo grove (sold to provide the family with money to modernise their house). Samojiro Watanabe's A Secret Secret Mountaineering with Grandpa offers a similar narrative of male inheritance in the face of loss. Grandfather and grandson engage in a kind of initiation rite in the absence of Kenta's parents. They leave the domestic space of the family home to walk in the mountains in search of the char that adventurous Grandpa rescued and put into a high river years ago. Finding the fish, Grandpa acknowledges that he can no longer monitor them and passes the responsibility to his grandson. Having undergone the initiation rite and learned how to cope with danger and the unexpected, Kenta accepts his familial role, symbolised through his care for the fish. The positions of grandfather and grandson in the images makes this clear: Kenta is initially positioned as subordinate to his grandfather (below, behind or being carried by him) (see Figure 10.4), but after they find the fish, they are seen from behind standing close together, and Grandpa has his arm on his grandson's shoulders (see Figure 10.5). This book hints at a changing world through the threat to the fish (they have been overfished for fun, not food), which is tied up with Grandpa's increasing frailty. Nonetheless, the book seeks to overcome this threat, symbolically, by a successful exchange of caring roles, rooted in a masculinity associated with danger, strength and protection of the vulnerable.

A narrative of male lineage is also central in Jibun no ki [One's Tree] (Mogami and Matsunari, 2009), in which the illness of a greatgrandparent necessitates the development of the child. Set in a remote, depopulated village, One's Tree depicts the connection between Wataru and his 93-year-old great-grandfather. Wataru listens to the great-grandfather's past as a bear hunter and his love for the mountainous environment in which they live, especially Mt. Asahidake. This environment is depicted in vivid colours in thick brush strokes throughout the book. As in many other books, the middle generation is entirely absent, isolating the child and great-grandfather to emphasise their intimacy. The trope of travelling alone features in this book, too, as the great-grandfather's illness forces his move to a hospital in the nearby town, meaning that Wataru has to travel for an hour to see him. Images of Wataru on his bicycle, a tiny figure in the lush green surroundings, and later his anxiety in the unfamiliar space of 

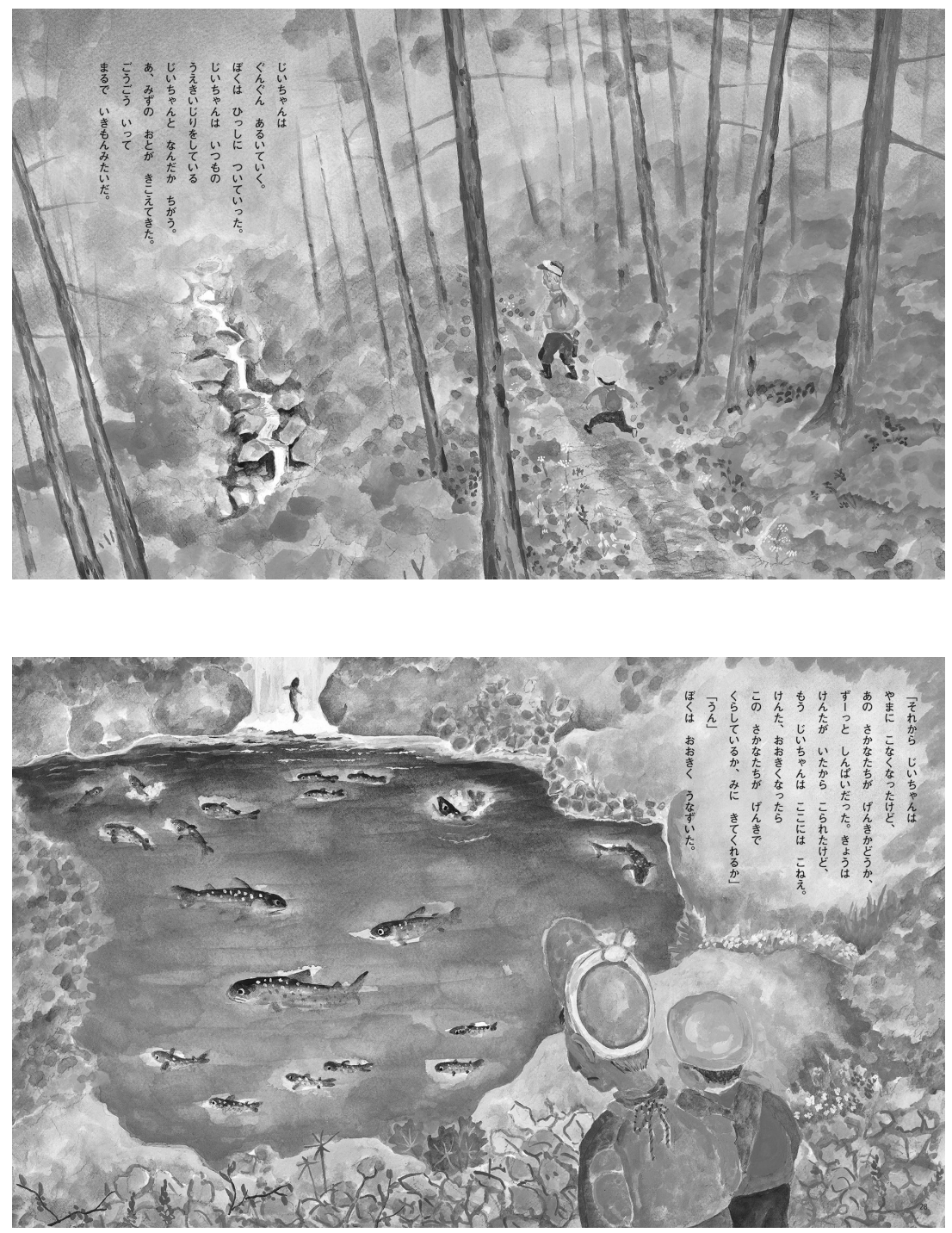

Figures 10.4 and 10.5 A Secret, Secret Mountaineering with Grandpa [Jiichan to naishonaisho no yamanobori], reproduced with permission of Suzuki Publishing Co., Ltd.

Source: () Samojiro Watanabe.

the hospital, painted in pale colours, suggest the challenges he faces in order to mature. One episode then clearly marks the exchange of care between the two generations: to fulfil his great-grandfather's wish to see Mt. Asahidake once more, Wataru gazes at the mountain so as to 

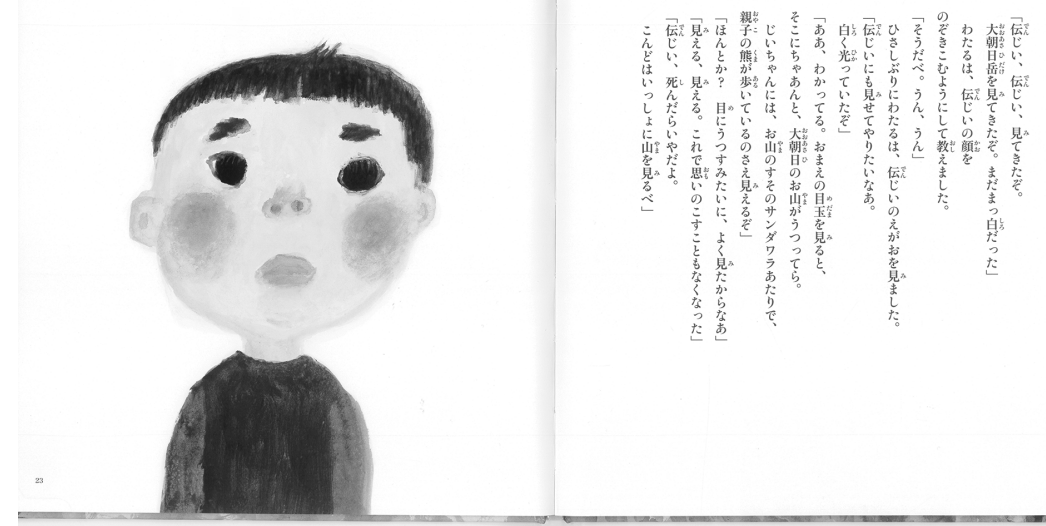

Figure 10.6 One's Tree [Jibun no ki], reproduced with permission of Iwasaki Shoten.

Source: ( Ippei Mogami and Mariko Matsunari.

"print it on my [his] eyes" and delivers the image to his dying greatgrandfather (22). On the right page of a double spread, we see the conversation between the two, in which the great-grandfather confirms that he can see the mountain in Wataru's eyes (22). The illustration on the left page (23) shows Wataru alone, his eyes large and black against a blank background (see Figure 10.6). Depicted from the perspective of the great-grandfather, the child looks sad, and his pink cheeks exaggerate his childishness. Nonetheless, this is also an image of a child who is called upon to be strong, an image that stares back at the child reader as much as at the great-grandfather. ${ }^{14}$

\section{Vulnerability and Dependency of Grandparents}

Promoting reciprocity and duty in relation to familial care, the picturebooks present a model of care that is premised upon the relational understanding of self and dependence but that relies upon gendered responsibilities. There are also signs in these books of the paradoxical impact that strong relationality and familial reciprocity may have. Though the books do not stigmatise the receipt of care in older age, some texts depict the individualisation of responsibility and shame about dependence as the result of strong intergenerational duty and responsibility. 


\section{2}

Katsura Sako and Sarah Falcus

The centrality of obligation in generational relationships in these books means that grandparents' receipt of care is naturalised and is rarely represented as a threat to their sense of self, as the stories of mirrored generations in Yuko and Grandma Fumi make clear. Generational care is explicitly endorsed in books that point to the moral and social value of the child's caring through praise voiced by a grandparent or other older character, as in Yuko and Grandma Fumi and other books, such as Ojichan no machi [Grandpa's Town] (Nomura, 1989). At the same time, some books signal that, though reciprocity may be assumed, dependency is something that should be avoided. In these books, grandparents apologise and feel guilt because illness means that they are dependent on others' care and/or they become a "burden" to their families. This can be seen in stories like Grandma is Kaguyabime, where the grandmother apologises after hurting her foot and being unable to cut bamboo (see also Grandpa's Paradise, Paradise and Daisukina obachan [My Dear Grandma] (Koyama and Fukuda, 1991)). These books then depict autonomy itself as relational and secured by taking responsibility for the impact of one's own actions on others, in this case, primarily family members. This model of autonomy may be culturally inflected, as we suggested earlier. The shame expressed about dependence in these books may also reflect the impact of neoliberalism in Japan in recent decades, where older people are under increasing pressure to "become (self) disciplined bodies" (Traphagan, "Being" 271) to spare society the burden of their care. Either way, it is significant that these books, while instilling a duty to care for older people in children, also indicate independence as a norm. This seemingly paradoxical attitude towards autonomy and dependence may be cultural, but it may also be an expression of anxieties about the impact of care needs on subsequent generations.

Ojichan no dobutsuen [Grandpa's Zoo] (Asano and Asano, 2002) clearly illustrates the paradox of the strong relationality at the core of family care. In the book, a grandchild narrates the story of his grandfather's realisation of a long-held dream to live with many animals. After his retirement, Grandpa moves to a rural area to run a farm and menagerie. He is eventually joined there by his grandchildren and family. Colourful images stress the active nature of farm life. But as Grandpa brings in more and more animals, the images show the other family members to be dismayed, rather than pleased, and a sequence of images and text describes the tasks involved in caring for so many animals. Grandpa eventually falls ill immediately after nursing a monkey back to health, implying that his illness and associated need for care are a direct result of his animal ownership (and, therefore, his individual dream). The animals are then a burden on the other family members, and the text describes Grandpa's sadness and worry about this. Specifically, he relates this to his own future frailty: "As I grow even older, and my body stops working, what will happen?" (19). This link makes clear that the "burden" 
of caring for the animals is inherently linked to the "burden" of caring for older relatives. Upon his recovery, Grandpa begins to free some of the animals, recognising the need to curtail his own desire because of the impact of his decisions on other family members. At the same time, Grandpa's family decides to distribute roles more equitably and work together. It is therefore through turning Grandpa's individual dream into a familial project that the book de-stigmatises his choice to follow his own dreams. A further community-based responsibility is fulfilled when "Grandpa's zoo" is opened to visitors, and Grandpa educates them about animal welfare. Picturebooks like Grandpa's Zoo then present a model of relational care that may ensure reciprocity but also restrict individual autonomy. They not only emphasise the duty to care embedded in generational relationships, but also suggest that there is a complex relationship between duty, responsibility and reciprocity.

\section{Conclusion}

These books about grandparents, grandchildren, illness and ageing are in many ways anachronistic, conservative and idealistic. They support the cultural discourse of familial and gendered care, inducting young children into a vision of intergenerational responsibility that is now very often unattainable. Espousing the duty of a child to care for older generations, they present the route to maturity (growing up) as one of relationality and the acceptance of familial obligation. Some books do express what we might call "hidden adult anxieties" about the threats to the very care and generational system they celebrate. Geographical separation and depopulation, for instance, signify these threats, as does the very force with which the texts assert a familial ideal that may be a long way from the reality of the lives of many families in contemporary Japan. The books contain these threats through the narrative of generational inheritance. They are evidence of both the persistence of the ideal of familial care in Japan and the desire to secure the future of that ideal in the next generation.

At the same time, these books contain signs of limitations to the ideal of reciprocity at the heart of familial care. The complexity of what Hashimoto calls "symbolic equity" in generational economies of care is indicated in those books where older people feel guilt about their own dependence and the associated need for care from family members. Although relational care has been considered in positive terms in recent decades as an antidote to harmful individualism in Western societies, the intergenerational familial care in these Japanese books suggests that relationality works in complex ways, ways that are also culturally conditioned. Furthermore, the shame attached to dependency may also reflect the neoliberal individualisation of care responsibility. In June 2021, the Japanese government passed a bill to oblige more 


\section{Katsura Sako and Sarah Falcus}

people over 75 to contribute $20 \%$, not the current $10 \%$, towards their medical costs. The official justification for this change - that it would lessen the burden on younger generations - has been questioned by estimates suggesting its limited impact on younger people, and concerns have been raised that yet more older people would be left unable to pay for their healthcare. The idealisation of family care in these contemporary picturebooks is therefore a reflection of a society that struggles to find new ways to care.

\section{Acknowledgements}

Research for the present study is supported by the Japan Society for the Promotion of Science (KAKENHI: 17KK0030). The authors are also grateful to the three bilingual students from Sako's cultural gerontology class who translated the picturebooks into English.

\section{Notes}

1. In 2019, Japan's total fertility rate was 1.36 (Ministry of Health, "Reiwa" 4 ), and life expectancy at birth was 81.41 (men) and 87.45 (women) (Ministry of Health, "Abridged" 1). Among countries in The Organisation for Economic Co-operation and Development (OECD), Japan has the highest old-age dependency ratio at over 50 people aged $65+$ for every 100 people aged 20-64 (OECD).

2. The SLA's annual writing competition, which began in 1956, now attracts 4 million submissions every year (School Library Association).

3. From a reference book of children's picturebooks published in Japan 19582010 (DB Japan), we selected texts published in Japanese after 1980 that focus on older adult/child relationships (usually grandparent and grandchild). Adding more recent publications to the selection, we had 75 texts translated into English by three research assistants. Following more detailed analysis, we selected 46 texts that most prominently explored ageing and care in the context of intergenerational relationships. Translations of the picturebook titles and texts in this chapter are either based on or modified from those produced by the assistants.

4. See Traphagan (Rethinking Ch. 3) for a useful overview of these scholarly works.

5. Cases of harassment towards those with COVID-19 in Japan seem to highlight this individualism. In an interview, historian Jun Yohana connects the harassment to "negative individualism" (funo kojinshugi) that makes it a moral norm not to trouble others ("Kansensha;" translation by Sako). Similarly, an online survey in March/April 2020 found that $11.5 \%$ of respondents in Japan, in contrast to $1 \%$ in the US and $1.5 \%$ in the UK, agreed with the statement that "I think anyone who gets infected with the Coronavirus (COVID-19) got what they deserved" (Hirai et al.).

6. According to a 2019 survey by the Ministry of Health, Labour and Welfare, $5.1 \%$ of households in Japan include three or more generations (down from $15.3 \%$ in 1986$), 19.6 \%$ of people aged $65+$ live alone, $40.4 \%$ live with a spouse and $35.9 \%$ live with a child/children ("Summary" 3, 6). Ueno also 
makes the point that multi-generational living is not simply cultural but is also socio-economic (Kea, 95).

7. The monthly contribution for those aged $65+$ doubled by 2020 and is expected to continue to rise (Yamamoto).

8. The number of these deaths among people aged $65+$ in Tokyo has increased from 1,441 in 2003 (Kaneoke et al.) to 3,176 in 2019 (Bureau).

9. In a 2019 survey, $72.7 \%$ of primary co-resident caregivers who provide care "almost all day" were women (40.9\% were spouses, $19.8 \%$ daughters, and $7.3 \%$ a child's spouse) ("Summary" 27).

10. For instance, Ojichan no gokurakugokuraku [Grandpa's Paradise, Paradise] (Nishimoto and Hasegawa, 2006) and Obachan ga iruto iinonina [I Wish Grandma Was Here] (Matsuda and Ishikura, 1994) were on the list of books for the SLA's annual, nationwide writing competition. Award-winning Daijobu daijobu [It's Okay, It's Okay] (Ito, 1995) had been reprinted 34 times by 2008 .

11. This is based on content, contextual information such as that available on publishers' websites and the use (or absence) in the books of Chinese characters, the learning of which is integrated into the Courses of Study for primary schools by the Ministry of Education, Culture, Sports, Science and Technology.

12. The English translations of the picturebook titles are used in second and later references.

13. Daisukina obachan [My Dear Grandma] (Hinohara and Okada, 2014) contains a rare example of professional palliative care. The author, who died in 2017 at the age of 105, was a well-known doctor and advocate for endof-life care in Japan. Even here, though, the mother also provides practical care.

14. This moral lesson is also reinforced, throughout the book, by the instructive voice of the third-person narrative: in dialogue, the boy's voice reflects his age and gender, but the third-person narrative evokes a more mature perspective in its use of language. It also uses "desu," a participle that is used to end a sentence in a speech addressed to others.

\section{Works Cited}

\section{Primary Sources}

Asano, Yoko, and Teruo Asano. Ojichan no dobutsuen. Bunka Publishing Bureau, 2002.

Furiya, Kayoko. Chiko-chan no akai chokki. Popular Publishing, 1987.

- Obachan no shima de. Bunken Shuppan, 1995.

Hinohara, Shigeaki, and Chiaki Okada. Daisukina obachan. Asahi Shimbun Publications, 2014.

Imamura, Ashiko, and Nana Furiya. Futari ha dadakko. Doshinsha Publishing, 1995.

Ito, Hiroshi. Daijobu daijobu. Kodansha, 1995.

Kasai, Mari, and Kotaku Yoshinaga. Bachan no onaka. Kyoiku gageki, 2010.

Kimura, Fumiko, and Kahoru Kimura. Hitoride omimai. Kokudosha, 1991.

Koyama, Yoshiko, and Iwao Fukuda. Daisukina obachan. Daughters of St. Paul, 1991.

Matsuda, Motoko, and Fukiko Karino. Obachan ha kaguyahime. Popular Publishing, 2013.

—, and Kinji Ishikura. Obachan ga iruto iinonina. Popular Publishing, 1994. 


\section{Katsura Sako and Sarah Falcus}

Miyakawa, Hiro, and Kinji Ishikura. Yuko to Fumi bachan. Akane Shobo, 1983. Mogami, Ippei, and Mariko Matsunari. Jibun no ki. Iwasaki Shoten, 2009.

Nagano, Hideko. Obachan ga obachan ni nattahi. Doshinsha, 2015.

Nakajima, Kotobuki et al. Obachan to warabeuta. Taihei Shuppansha, 1997.

Nishimoto, Keisuke, and Fukiko Karino. Sayonara, obachan. Koseisha, 2010.

- , and Yoshifumi Hasegawa. Ojichan no gokurakugokuraku. Suzuki Shuppan, 2006.

Nomura, Takayuki. Bachan no engawa. Kodansha, 1983.

- Ojichan no machi. Kodansha, 1989.

Okada, Yutaka, and Yoshitaka Shinohara. Jishinkaminarikaji jichan. Popular Publishing, 1987.

Sueyoshi, Akiko, and Suzuko Makino. Maho ha naishode kakeyone. Hikumano Shuppan, 1984.

Watanabe, Samojiro. Jichan to naishonaisho no yamanobori. Shuzuki Shuppan, 2007.

Watanabe, Shigeo, and Toshio Kajiyama. Yukkurayukkura yotayota. Akane Shobo, 1982.

\section{Secondary Sources}

Aoyama, Tomoko. "The Girl-Grandmother Relation in Japanese Children's Literature." Configurations of Family in Contemporary Japan. Edited by Tomoko Aoyama et al. Routledge, 2014, pp. 49-64.

Aoyama, Tomoko et al. "Introduction." Configurations of Family in Contemporary Japan. Edited by Tomoko Aoyama et al. Routledge, 2014, pp. 1-5.

Arichika, Takashi et al. "Kaigo to watashitachi 2025-nen mondai heno kadai sonzaikan masu 'kaigo Yobo' 'Jiritsu shien'." Asahi Shimbun (Morning issue), 6 Dec. 2020, p. 4.

Bureau of Social Welfare and Public Health, Tokyo Metropolitan Government. "Tokyo to kansatsuimuin de toriatukatta jitaku jukyo de nakunatta tanshin setai no mono no toukei (Reiwa gannen)." Tokyo Metropolitan Government, 2021, www.fukushihoken.metro.tokyo.lg.jp/kansatsu/kodokushitoukei/kodokushitoukei-1.files/31-tokubetuku.pdf.

Coulmas, Florian. Population Decline and Aging in Japan: The Social Consequences. Routledge, 2007.

Danely, Jason. Aging and Loss: Mourning and Maturity in Contemporary Japan. Rutgers UP, 2015.

DB Japan. Tema, janru kara sagasu monogatari ohanashi ehon 1: Kodomono sekai seikatsul kaku no mono fantajil norimono/waraibanashi yumoa. DB Japan, 2011.

Gilligan, Carol. In a Different Voice: Psychological Theory and Women's Development. Harvard UP, 1982.

Gubar, Marah. "Risky Business: Talking about Children in Children's Literature Criticism.” Children's Literature Association Quarterly, vol. 38, no. 4, 2013, pp. 450-7, https://doi.org/10.1353/chq.2013.0048.

Hashimoto, Akiko. The Gift of Generations: Japanese and American Perspectives on Aging and the Social Contract. Cambridge UP, 1996.

Henneberg, Sylvia. "Moms Do Badly, but Grandmas Do Worse: The Nexus of Sexism and Ageism in Children's Classics." Journal of Aging Studies, vol. 24, 2010, pp. 125-34. 
Hisaoka, Miyuki. "Cooperation and Negotiation: Formation of Subjectivity in Japanese and Australian Picture Books." Subjectivity in Asian Children's Literature and Film: Global Theories and Implications. Edited by John Stephens. Routledge, 2012, pp. 59-77.

Honda, Masuko. "Ehon.” Nihon jido bungaku gairon. Edited by Nihon jido bungaku gakkai. Tokyo Shoseki, 1976, pp. 119-27.

—. Kodomo hyakunenno epokku: "Jidono seiki" kara "Kodomonokenrijoyaku” made. Froebel-kan, 2000.

Hirai, Kai et al. "Shingatakorona uirusu kansenka ni kakawaru shakaishinrigakukenkyu (webu chosa) johomatome.” Osaka University, 2021, https://docs.google.com/ document/d/e/2PACX-1vQFIr9pEwwUV7I0FkzUC_c8OpZrqkUPEYytQFeViIV86zgGUnM_wZeIvserq2Aevyw-ajmq3en7duW/pub.

Izuhara, Misa. "Care and Inheritance: Japanese and English Perspectives on the 'Generational Contract.'” Ageing and Society, vol. 22, 2002, pp. 61-77.

Joosen, Vanessa. "Second Childhoods and Intergenerational Dialogues: How Children's Literature Studies and Age Studies Can Supplement Each Other." Children's Literature Association Quarterly, vol. 40, no. 2, 2015, pp. 126-40.

sissippi P, 2018.

Kaneoke, Yoshimasa et al. Tokyo nijusanku ni okeru kodokushi tokei (Heisei 15-19 nen): Setai bunruibetsu ijoshi tokei chosa. Edited by Bureau of Social Welfare and Public Health. Tokyo Metropolitan Government, 2011, www. fukushihoken.metro.tokyo.lg.jp/kansatsu/kodokushitoukei/kodokushitoukei. files/04_dai2syou.pdf.

"Kansensha o semeru watashitachi." Asahi Shimbun (Morning issue), 9 Oct. 2020, p. 13.

Karatani, Kojin. Teihon nibon kindai bungaku no kigen. 1980. Iwanami Shoten, 2008. Translated into English as Origins of Modern Japanese Literature. Duke UP, 2003.

Kasuga, Kisuyo. “'Shinguru ko’ to dokyosuru koreishakazoku no kaigokiki: Kyurai no kazokukan kara dakkyaku o." Homon kaigo to kaigo, vol. 17, no. 2, 2012, pp. 119-23.

Katz, Stephen, and Toni Calasanti. "Critical Perspective on Successful Ageing: Does It 'Appeal More Than It Illuminates'?” The Gerontologist, vol. 55, no. 1, 2015, pp. 26-3.

Kavedžija, Iza. "The Age of Decline? Anxieties about Ageing in Japan.” Ethnos, vol. 81, no. 2, 2016, pp. 214-37.

Kittay, Eva Feder. Love's Labor: Essays on Women, Equality, and Dependency. Routledge, 1999.

- et al. "Dependency, Difference and the Global Ethic of Long-Term Care." The Journal of Political Philosophy, vol. 13, no. 4, 2005, pp. 443-69.

Lamb, Sarah. "Beyond the View of the West: Ageing and Anthropology." Routledge Handbook of Cultural Gerontology. Edited by Julia Twigg and Wendy Martin. Routledge, 2015, pp. 37-44.

Ministry of Heath, Labour and Welfare. “Abridged Life Tables for Japan 2019.” Ministry of Health, Labour and Welfare, 2019, www.mhlw.go.jp/english/database/db-hw/lifetb19/dl/lifetb19-06.pdf.

—. "Reiwa gannen (2019) jinko dosei tokei (kakuteisu) no gaikyo." Ministry of Health, Labour and Welfare, 2019, www.mhlw.go.jp/toukei/saikin/hw/ jinkou/kakutei19/index.html. 


\section{Katsura Sako and Sarab Falcus}

"Summary Report of Comprehensive Survey of Living Conditions 2019." Ministry of Health, Labour and Welfare, 2019, www.mhlw.go.jp/english/data base/db-hss/dl/report_gaikyo_2019.pdf.

Miura, Seiko. "1990 nendai no ehon: Ketsujitsu to hatten to." Torigoe, Hajimete, 2002, pp. 183-202.

Nakagawa, Takeshi, and Yasuyuki Gondo. "Health Care System and Policy Implications for Older Adults in Japan." Healthy Aging in Sociocultural Context. Edited by Andrew E. Scharlach and Kazumi Hoshino. Routledge, 2012, pp. 53-61.

Nikolajeva, Maria. Power, Voice and Subjectivity in Literature for Young Readers. Routledge, 2010.

Noddings, Nel. Caring: A Feminist Approach to Ethics and Moral Education. U of California P, 1984.

Nodelman, Perry. The Hidden Adult: Defining Children's Literature. John Hopkins UP, 2008.

OECD. "Working Better with Age: Japan." 2018, www.oecd-ilibrary.org/ sites/9789264201996-en/index.html?itemId=/content/publication/9789264 201996-en.

Oomachi, Yukina. "Ema obachan ga egaku pojiteibu eijingu - jendaka shita eijingu wo ikiru 'obasan' ko." Ehongaku: Ehon gakkai kenkyu kiyo, vol. 10, 2008, pp. 53-8.

Rudd, David. "Theorising and Theories: The Conditions of Possibility of Children's Literature." International Companion Encyclopedia of Children's Literature. Edited by Peter Hunt. Routledge, 2004, pp. 29-43.

Sasaki, Takayuki. "Healthy Aging and Intergenerational Intervention in Japan." Healthy Aging in Sociocultural Context. Edited by Andrew E. Scharlach and Kazumi Hoshino. Routledge, 2012, pp. 62-71.

School Library Association. Official Website. www.j-sla.or.jp/contest/youngr/

Takahashi, Hisako. "1960 nendai no ehon: Atarashii kodomobunka no kouchikuhe." Torigoe, Hajimete, 2002, pp. 147-64.

Takeda, Kyoko. "A Gender Gap in 'Kodomonotomo'." The Journal of the Center for Educational Research and Practices, vol. 9, 1999, pp. 51-61.

_- "Ehon no nakano kazoku: Gekkan monogatari ehon Kodomonotomo ni mirareru kazokuishiki." Japan Society of Research on Early Childhood Care and Education Convention Proceedings, vol. 54, 2001, pp. 526-7.

Thang, Leng. "Aging and Social Welfare in Japan." Routledge Handbook of Japanese Culture and Society. Edited by Victoria Bestor et al. Routledge, 2011.

Tokoro, Michihiko. "Ageing in Japan: Family Changes and Policy Developments." Ageing in East Asia: Challenges and Policies for the Twenty-First Century. Edited by Tsung-hsi Fu and Rhidian Hughes. Routledge, 2009, pp. 54-71.

Torigoe, Shin. "Sengo jidobungaku no gojunen o gaikansuru: Futatabi meguttekita kikino jidai no nakade." Sengo jido bungaku no 50 nen. Edited by Nihon jido bungakusha kyokai. Bunkei-do, 1996, pp. 8-19.

- editor. Hajimete manabu nibon no ehon shi III - Sengo ehon no ayumi to tenbo. Minerva Shobo, 2002.

Traphagan, John W. "Being a Good Rojin: Senility, Power, and Self-Actualization in Japan." Thinking About Dementia: Culture, Loss, and the Anthropology of Senility. Edited by Annette Leibing and Lawrence Cohen. Rutgers UP, 2006, pp. 269-87. 
Rethinking Autonomy: A Critique of Principlism in Biomedical Ethics. State U of New York P, 2013.

Ueno, Chizuko. Kea no shakai gaku-Tojisha no fukushi shakai he. Ohtabooks, 2011.

_. "Family Strategy on Care: Norms, Preferences, and Resources." Japanese Journal of Family Sociology, vol. 25, no. 1, 2013, pp. 30-42.

White, Merry Isaacs, Perfectly Japanese: Making Families in an Era of Upheaval. U of California P, 2002.

Yamamoto, Kyosuke. "Rising Number of Elderly in Arrears on Nursing Care Insurance." The Asahi Shimbun, 12 Oct. 2020, www.asahi.com/ajw/ articles/13810553. 